\title{
Review Study on Larvicidal and Mosquito Repellent Activity of Volatile Oils Isolated from Medicinal Plants
}

\author{
Prabakaran $\mathrm{P}^{1}$, Sivasubramanian $\mathrm{C}^{2}$, Veeramani $\mathrm{R}^{3}$ and Prabhu $\mathrm{S}^{4}$ \\ ${ }^{1,3}$ Ph.D., Research Scholar, Department of Environmental and Herbal Science, Faculty of Science, Tamil University, Thanjavur, \\ Tamil Nadu, India. \\ ${ }^{2}$ Associate Professor and Head, Department of Environmental and Herbal Science, Faculty of Science, Tamil University, \\ Thanjavur, Tamil Nadu, India. \\ ${ }^{4}$ Ph.D., Research Scholar, Department of Siddha Medicine, Faculty of Science, Tamil University, Thanjavur, Tamil Nadu, India.
}

\begin{abstract}
Mosquito is a vector for serious human diseases like dengue fever, hemaorrhagic dengue fever and chikungunya, .yellow fever, malaria, filaria and encephalitis among these dengue, hemaorrhagic dengue and chikungunya are highly endemic diseases in Southeast Asian and African countries, causing millions of deaths each and every year. Mosquito repellents thus play a major role in preventing man-mosquito contact and there by minimize the chance of infections and its adverse effects. The development of resistance to chemical insecticides, results rebounding vectorial capacity. Synthetic repellents are chemicals which used worldwide for protection against mosquito-borne diseases and it adversely affects the environment by contaminating water, soil and air. There is an urgent need to find alternatives to the synthetic insecticides. Plants are rich source of alternative agents for control of mosquitoes and its vectors. Extracts and isolated compounds from different plant families have been evaluated for their promising larvicidal and mosquito repellent activities. Literature has documented that essential oils and extracts have been traditionally used as effective repellents. The essential oils whose repellent activities have been demonstrated, as well as the importance of the synergistic effects among their components are the main focus of this review study. Essential oils are volatile mixtures of hydrocarbons with a diversity of functional groups, and their repellent activity has been linked to the presence of monoterpenes and sesquiterpenes. The present review study focused the larvicidal potential and mosquito repellent activity of different volatile oils of medicinal plants. From an economical point of view synthetic chemical is still more frequently used as repellents than essential oils; these essential oils have the potential to provide efficient and can be used as a cheap, eco-friendly, safer for humans and the environment and also efficient alternative to the chemical larvicides.
\end{abstract}

Keywords - Essential oils, Larvicidal activity, Medicinal Plants, Mosquito repellents, Volatile oils.

\section{INTRODUCTION}

Mosquitoes transmit serious human diseases, causing millions of deaths every year and the development of resistance to chemical insecticides, resulting in rebounding vectorial capacity. Mosquito has approximately 3500 species and present in tropical and subtropical regions of the world [1].Major genera of mosquitoes that act as vector for various disease including dengue, chikungunya, malaria, yellow fever, filariasis, Japanese encephalitis, Lyme disease, andepidemic polyarthritis [2, 3]. Among these mosquito borne diseases dengue, fever dengue hemaorrhagic fever, yellow fever and chikungunya are endemic in Southeast Asian countries [4]. These are transmitted by Aedes aegypti (Linn.) [5] Anopheles stephensi and Culex quinquefasciatus. Mosquito repellents thus play a major role in preventing man-mosquito contact and there by minimize the chance of infectious diseases. Synthetic repellents, such as DEET (Diethyl-metatoluamide or N, N- diethyl-3-methyl benzamide (IUPAC Name)), are used worldwide for protection against mosquito-borne diseases. However, DEET has an unpleasant odor, can damage plastics and synthetic rubber and exhibits a high level of skin penetration [6]. Moreover, concerns have been raised over the safety of DEET and other synthetic compounds [7]; one of the methods available for controlling the mosquitoes is use of synthetic insecticides. Synthetic insecticides adversely affect the environment by contaminating water, soil and air. There is an urgent need to find alternatives to the synthetic insecticides.

Plants and its isolated compounds are alternative agents for control of mosquitoes, because they possess bioactive chemicals, which act against limited number of species including specific target-insects and are eco-friendly [8].Traditionally plant based products have been used in human communities for many centuries for managing insects. Several secondary metabolites present in plants serve as a defense mechanism against insect attacks. These bioactive chemical may act as insecticides, repellents, antifeedants, moulting hormones, juvenile hormone mimics, growth inhibitors, anti-moulting hormones as well as 
attractants. Plant based pesticides are less toxic, delay the development of resistance because of its new structure and easily biodegradable [9].

Several plant extracts and isolated compounds from different plant families have been evaluated for their promising larvicidal activities [10]. About 2000 species of terrestrial plants have been reported for their insecticidal properties [11]. Medicinal plants are more potent, eco-safe and low-cost which is easily available and have become increasingly popular as safe and biodegradable mosquito repellents [12], it is less or no adverse effect to the environment.

Plant based products does not have any hazardous effect on ecosystem. Recent research has proved that effectiveness of plant derived compounds, such as saponine [13], steroids [14, 15], isoflavonoids [16], essential oils [17], alkaloids and tannins [18] has potential mosquito larvicides. Plant secondary metabolites and their synthetic derivatives provide alternative source in the control of mosquito [19, 20].

\subsection{Mode of action of essential oils}

Essential oils being complex mixtures of volatile organic compounds are generally produced as secondary metabolites in plants. They are constituted by hydrocarbons (terpenes and sesquiterpenes) and oxygenated compounds (alcohols, esters, ethers, aldehydes, ketones, lactones and phenols). Essential oils have high repellency against arthropod species [21]. Literature has documented that essential oils and extracts have been traditionally used as effective repellents. The metabolites like the monoterpenes such as $\alpha$-pinene, cineole, eugenol, limonene, terpinolene, citronellol, citronellal, camphor and thymol are the common constituents in a number of essential oils presenting mosquito repellent activity [22]. Literature cites that hairs on the mosquito antennae are temperature and moisture sensitive. The repellent molecules thus interacts with the female mosquito olfactory receptors thereby blocking the sense of smell which therefore comes as an hurdle in the recognition of host by the mosquitoes [23].

Elucidation of the mode of action of essential oils and their constituents is of practical importance for insect control because it may give useful information on the most appropriate formulation and delivery means. Volatile oil can disrupt communication in mating behavior of insect by blocking the function of antennal sensilla and unsuccessful mating could lead to a lower fecundity and ultimately lower the population of insect pest [24]. Rapid action of essential oils or its constituents against insect pests is an indicative of neurotoxic actions. The present review study carried out to validate the larvicidal potential and mosquito repellent activity of different volatile oils of medicinal plants.

\section{LITERATURE SURVEY}

Manimaran et al., evaluated larvicidal efficacy of the most promising oils such as mentha (Mentha piperita), clove (Myrtus caryophyllus) and calamus oils (Acorus calamus) which recorded low $\mathrm{LC}_{50}$ and $\mathrm{LC}_{90}$ values with $95 \%$ confidence lower and upper limits. Eucalyptus oil showed the least larvicidal activity with $\mathrm{LC}_{50}$ and $\mathrm{LC}_{90}$ values for larvicidal activity against Anopheles stephensi. Some plant oils also tested against Culex quinquefasciatus, the most promising oils were calamus, mentha and lemon oils which recorded $\mathrm{LC}_{50}$ andLC $\mathrm{C}_{90}$ values with $95 \%$ confidence lower limits and upper limits for larvidial activity. Citronella oil showed least larvicidal activity with $\mathrm{LC}_{50}$ and $\mathrm{LC}_{90}$ values. Among the oils against Aedes aegypti, Mentha, citronella and clove oils showed the most potent larvicidal activity and recorded $\mathrm{LC}_{50}$ and $\mathrm{LC}_{90}$ values with $95 \%$ confidence lower and upper limits. Eucalyptus oil showed the least effective larvicidal activity with $\mathrm{LC}_{50}$ and $\mathrm{LC}_{90}$ values [25]. Cavalcanti et al., reported the most active essential oils against third instar larvae of $A$. aegypti were those of $O$. gratissimun $\left(\mathrm{LC}_{50} 60 \mathrm{ppm}\right)$, O. americanum $\left(\mathrm{LC}_{50} 67 \mathrm{ppm}\right)$, L. sidoides ( $\left.\mathrm{LC}_{50} 63 \mathrm{ppm}\right)$, and C. citrates ( $\left.\mathrm{LC}_{50} 69 \mathrm{ppm}\right)$. They finally concluded the essential oils of $O$. americanum and $O$. gratissimun showed as potent as $L$. sidoides and $C$. citrates in the larvicidal activity against $A$. aegypti and caused $100 \%$ mortality at a concentration of 100 ppm [17]. Sukumar et al., reported that $C$. citrates causes significant growth inhibition and mortality in later developmental stages of A. aegypti [26].

One research study revealed that the essential oils from Mentha longifolia L., and Lavandula dentata L. were evaluated for their insecticidal and repellent activity against adult females of Culex pipiens L. This study concludes Lavandula dentata oil showed higher repellent activity than Mentha longifolia oil against adults of Culex pipiens; paraffin oil significantly prolonged the time of protection for the two oils. The longest time of protection was recorded $165 \mathrm{~min}$ for $L$ dentata oil, at $1 \mu \mathrm{l} / \mathrm{cm}^{2}$, when the tested oils were applied in paraffin oil. The researcher suggested the two oils were effective as repellent substances when compared with commercial materials and also recommended further studies to isolate the most effective mosquito control agents from these oils [27].

Using a GC/MS, 24, 17, 20, 21, and 12 compounds were determined by Nataya Sutthanont et al., from essential oils of Citrus hystrix, Citrus reticulata, Zingiber zerumbet, Kaempferia galanga, and Syzygium aromaticum, respectively. The author analysed the principal constituents found in peel oil of $C$. hystrix were $\beta$-pinene and $d$ limonene, followed by terpinene-4-ol. Compounds in $C$. reticulata peel oil consisted mostly of $d$-limonene and $\gamma$ terpinene. The oils obtained from $Z$. zerumbet rhizome had $\alpha$-humulene and zerumbone as major components. The most abundant compounds in $K$. galanga rhizome oil were 2propeonic acid, pentadecane, and ethyl-p-ethoxycinnamate. The main component of $S$. aromaticum bud oil was eugenol, with minor amounts of trans-caryophyllene. The researcher 
assessed larvicidal efficacy and demonstrated that all essential oils were toxic against both pyrethroid-susceptible and resistant $A e$. aegypti laboratory strains at $\mathrm{LC}_{50}, \mathrm{LC}_{95}$, and $\mathrm{LC}_{99}$ levels. They conclude and documented the promising larvicidal potential of essential oils from edible herbs, which used in controlling vectors of mosquito borne disease [28].

Pavela et al., documented twenty samples of essential oils obtained from Mentha aquatica, M. longifolia, M. spicata, M. suaveolens, M. piperita, M. piperita var. crispa, $M$. villosa, and Pulegium vulgare were tested for larvicidal activity against Culex quinquefasciatus. Essential oils obtained via hydro-distillation and subsequently analysed by gas chromatography-mass spectrometry (GC-MS). The researcher analysed the concentrations causing $50 \%$ or $90 \%$ larval mortality. Finally they conclude essential oils of $M$. longifolia and $M$. suaveolens, which were containing a majority of piperitenone oxide, and also had the highest larvicidal effects [29].

Table.1: Essential Oils that have shown Larvicidal and Mosquito Repellent Activity.

\begin{tabular}{|c|c|c|c|c|}
\hline $\begin{array}{c}\text { Vector's Scientific } \\
\text { name }\end{array}$ & Plant Species & Family Name & Plant Parts Used & Reference \\
\hline Aedes aegypti & Mentha piperita & Lamiaceae & Commercial & Manimaran et al., (2012) \\
\hline Aedes aegypti & Myrtus caryophyllus & Myrtaceae & Commercial & Manimaran et al., (2012) \\
\hline Aedes aegypti & Acorus calamus & Acoraceae & Commercial & Manimaran et al., (2012) \\
\hline Aedes aegypti & Сіппатотит & Lauraceae & Commercial & Manimaran et al., (2012) \\
\hline Aedes aegypti & zevlanicum & Cardiopteridaceae & Commercial & Manimaran et al., (2012) \\
\hline Aedes aegypti & Citronella mисronata & Myrtaceae & Commercial & Manimaran et al., (2012) \\
\hline Aedes aegypti & Eucalyptus tereticornis & Rutaceae & Commercial & Manimaran et al., (2012) \\
\hline Aedes aegypti & Citrus limon (L.) & Rutaceae & Commercial & Manimaran et al., (2012) \\
\hline Aedes aegypti & Citrus sinensis & Rutaceae & Dried Fruits & Choochote et al., (2007) \\
\hline Aedes aegypti & Zingiber piperitum & Compositae & N.A & Gillij et al., (2008) \\
\hline Aedes aegypti & Baccharis spartioides & Verbenaceae & N.A & Gillij et al., (2008) \\
\hline Aedes aegypti & Aloysia citriodora & Poaceae & Fresh aerial parts & Oyedele et al., (2002) \\
\hline Aedes aegypti & C. citratus & Lamiaceae & Leaves & Prajapati et al., (2005) \\
\hline Aedes aegypti & O. basilicum & Lamiaceae & Shoot & Prajapati et al., (2005) \\
\hline Aedes aegypti & Rosmarinus offinalis & Lauraceae & Bark & Prajapati et al., (2005) \\
\hline Aedes aegypti & Сіппатотит & Lamiaceae & Commercial & Trongtokit et al., (2005) \\
\hline Aedes aegypti & zeylanicum & Myrtaceae & Commercial & Trongtokit et al., (2005) \\
\hline Aedes aegypti & Pogostemon cablin & Rutaceae & Leaves & Trongtokit et al., (2005) \\
\hline Aedes aegypti & Syzygium aromaticum & Poaceae & Leaves & Trongtokit et al., (2005) \\
\hline Aedes aegypti & Z. limonella & Caryophyllaceae & Flowers & Tunon et al., (2006) \\
\hline Aedes aegypti & C. nardus & Caryophyllaceae & Flowers & Tunon et al., (2006) \\
\hline Aedes aegypti & D. caryophyllum & Lamiaceae & Leaves & Cavalcanti et al., (2004) \\
\hline Aedes aegypti & D. caryophyllum & Lamiaceae & Bloom & Cavalcanti et al., (2004) \\
\hline Aedes aegypti & Ocimum gratissimum & Geraniaceae & Leaves & Cavalcanti et al., (2004) \\
\hline Aedes aegypti & O. americanum & Poaceae & Bloom & Cavalcanti et al., (2004) \\
\hline Aedes aegypti & Pelargonium sidoides & Poaceae & Leaves & Sukumar et al., (1991) \\
\hline Aedes aegypti & C. citratus & Rutaceae & Leaves & Nataya et al., (2010) \\
\hline Aedes aegypti & C. citratus & Rutaceae & Leaves & Nataya et al., (2010) \\
\hline Aedes aegypti & Citrus histrix & Zingiberaceae & Fruits & Nataya et al., (2010) \\
\hline Aedes aegypti & Citrus reticulata & Zingiberaceae & Fruits & Nataya et al., (2010) \\
\hline Aedes aegypti & Zingiber zerumpet & Myrtaceae & Rhizome & Nataya et al., (2010) \\
\hline Anapheles stephensi & Kaemferia galanga & Lamiaceae & Rhizome & Manimaran et al., (2012) \\
\hline Anapheles stephensi & Syzygium aromaticum & Myrtaceae & Flower & Manimaran et al., (2012) \\
\hline Anapheles stephensi & Mentha piperita & Acoraceae & Commercial & Manimaran et al., (2012) \\
\hline Anapheles stephensi & Myrtus caryophyllus & Lauraceae & Commercial & Manimaran et al., (2012) \\
\hline Anapheles stephensi & Acorus calamus & Cardiopteridaceae & Commercial & Manimaran et al., (2012) \\
\hline Anapheles stephensi & Cinnaтотит & Myrtaceae & Commercial & Manimaran et al., (2012) \\
\hline Anapheles stephensi & zeylanicum & Rutaceae & Commercial & Manimaran et al., (2012) \\
\hline Anapheles stephensi & Citronella mисronata & Rutaceae & Commercial & Manimaran et al., (2012) \\
\hline Anapheles stephensi & Eucalyptus tereticornis & Lamiaceae & Commercial & Prajapati et al., (2005) \\
\hline Anapheles stephensi & Citrus limon (L.) & Lamiaceae & Commercial & Prajapati et al., (2005) \\
\hline Anapheles stephensi & Citrus sinensis & Lauraceae & Leaves & Prajapati et al., (2005) \\
\hline
\end{tabular}


Culex. quinquefasciatus

Culex. quinquefasciatus

Culex. quinquefasciatus

Culex. quinquefasciatus

Culex. quinquefasciatus

Culex. quinquefasciatus

Culex. quinquefasciatus

Culex. quinquefasciatus

Culex. quinquefasciatus

Culex. quinquefasciatus

Culex. quinquefasciatus

Culex. quinquefasciatus

Culex. quinquefasciatus

Culex. quinquefasciatus

Culex. quinquefasciatus

Culex. quinquefasciatus

Culex. quinquefasciatus

Culex. quinquefasciatus

Culex. quinquefasciatus

Culex. quinquefasciatus

Culex. quinquefasciatus

Culex. quinquefasciatus

Culex. quinquefasciatus

Culex. quinquefasciatus

Culex. quinquefasciatus

Culex. quinquefasciatus

Culex. quinquefasciatus

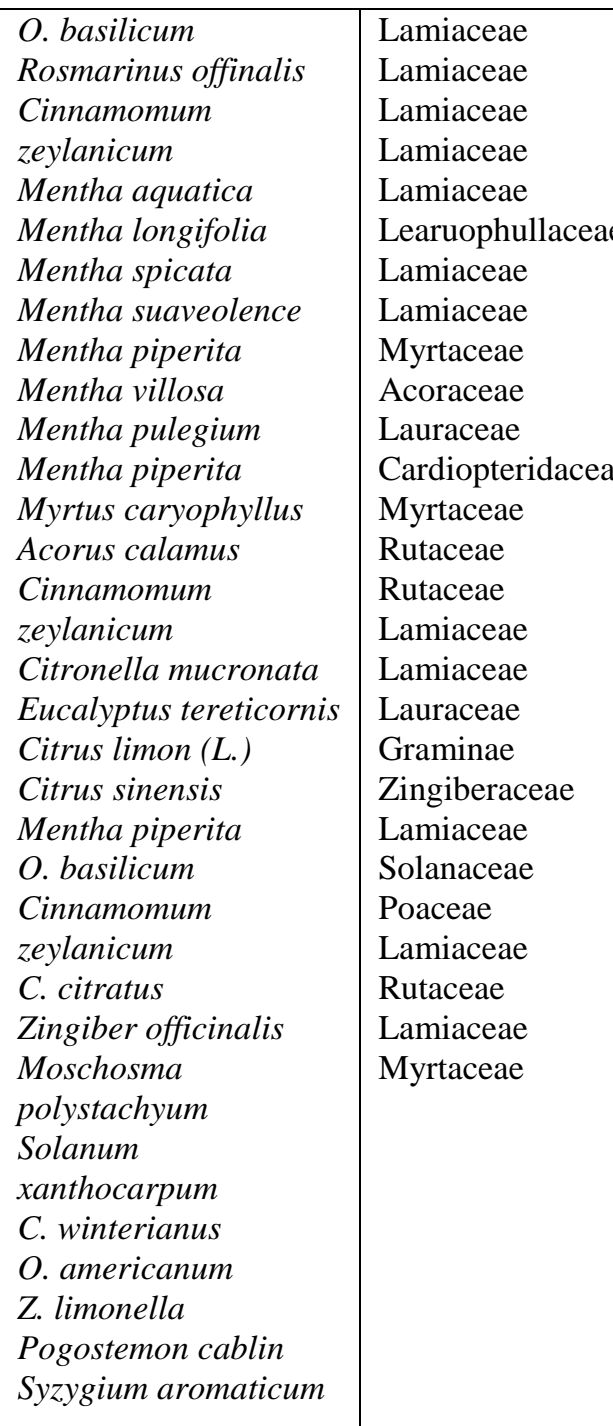

O. basilicum

Rosmarinus offinalis

eylanicum

Mentha aquatica

Mentha longifolia

entha spicata

Mentha suaveolence

Mentha piperita

Mentha villosa

Mentha pulegium

Mentha piperita

Myrtus caryophyllus

zeylanicum

Citronella mucronata

Eucalyptus tereticornis

Citrus limon (L.)

O. basilicum

Cinnamomum

eylanicum

C. citratus

ingiber officinali

Solanum

xanthocarpum

C. winterianus

americanum

Pogostemon cablin

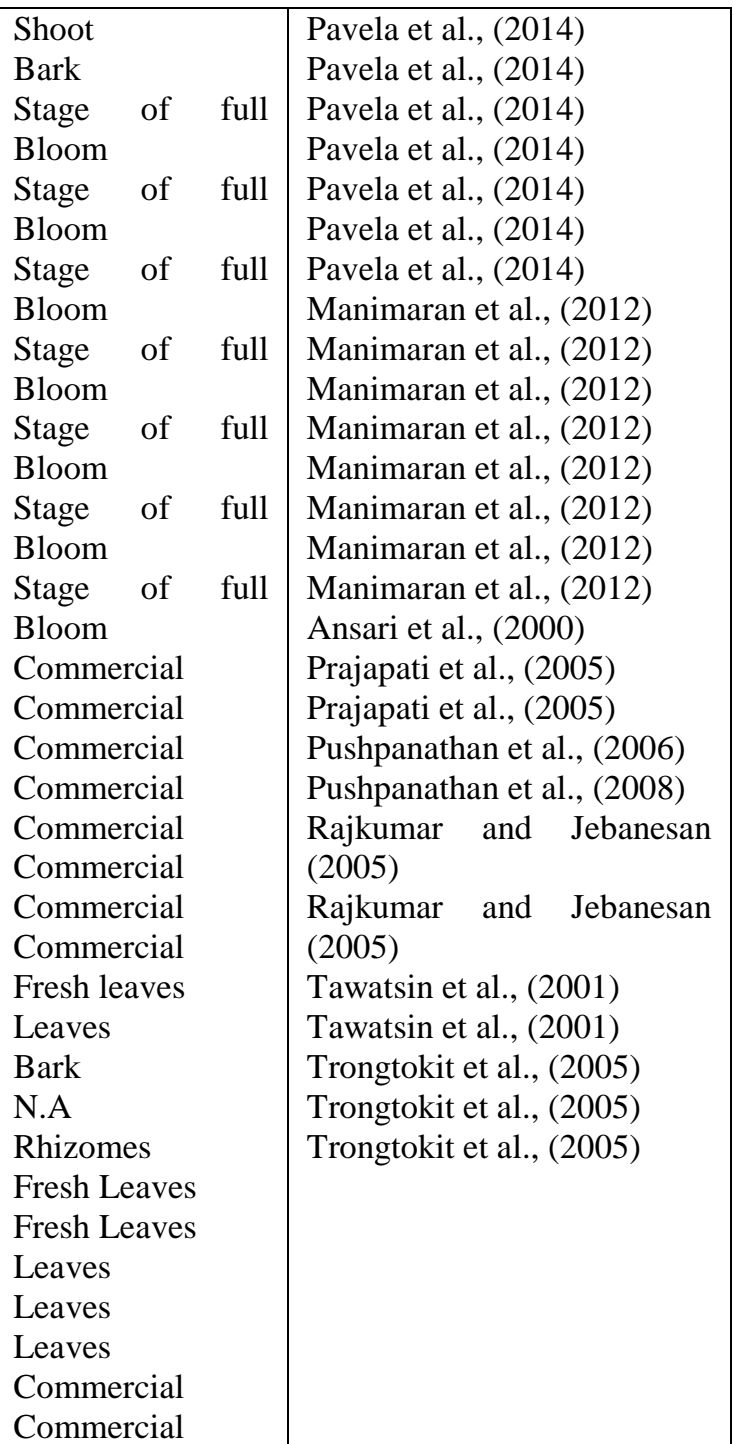

N.A - Not Available, Commercial - Essential oil purchased commercially.
One study revealed that the essential oil of Allium macrostemon bulbs and its two major constituents demonstrate strong larvicidal activity against Aedes albopictus mosquito larvae. The results suggested that the essential oil of A. macrostemon and the two major constituents may be recommended effectively in mosquito control, they also suggested further evaluation for safety in humans and to enhance their activity [30].

Rajkumar and Jebanesan, analysed essential oil obtained by steam distillation of leaves of Clausena dentata. Researcher observed the appearance of essential oil is colourless and a pleasant odour. The mean protection period of Clausena dentata essential oil at different concentrations against bite of Aedes aegypti was assessed by them. The results suggested that the organic solvent ethanol used in dilution of essential oil in protection period test did not showed positive irritant reaction. Both protection period and skinirritant tests recommend essential oil could be used as natural repellent that prevent man-dengue vector contact [31].

Manzoor et al., investigated five essential oils from various parts of five plant species such as Acorus calamus, Mentha arvensis, Ocimum basilicum, Saussrea lappa and Cymbopogan citratus for their larvicidal property against Aedes aegypti (L.) and Culex quinquefaciatus (Say) larvae and their results are the highest larvicidal activity was documented in the essential oil from $O$. basilicum against Ae. Aegypti (L.) and Cx. quinquefaciatus (Say) with $\mathrm{LC}_{50}$ values. Finally they concluded that essential oils had potential for controlling mosquito larvae [32].

Essential oil hydrolates of four plants such as Zanthoxylum limonella, Zingiber officinale, Curcuma longa and Cymbopogon citratus were evaluated for their larvicidal activity against two laboratory reared mosquito species Aedes albopictus and Culex quinquefasciatus. The researcher revealed that the hydrolate of $Z$. limonella was 
most effective against both Ae. albopictus and $C x$. quinquefasciatus with $\mathrm{LC}_{50}$ values. The larvicidal activity of hydrolates of $Z$. officinale, $C$. longa and $C$. citratus were also found promising with $\mathrm{LC}_{50}$ valuesagainst $A e$. albopictus and $C x$. quinquefasciatus [33].

Larvicidal bioassay carried out by Sarita Kumar et al., with the seed oil against early $\mathrm{IV}^{\text {th }}$ instars of Ae. aegypti caused $\mathrm{LC}_{50}$ and $\mathrm{LC}_{90}$ values after an exposure to 24 hours. The larvicidal effect of the celery seed oil augmented by 1.2fold; after an exposure to 48 hours; revealed $\mathrm{LC}_{50}$ values. The seed oil did not cause immediate larval mortality; researchers suggested a delayed toxicity against the larval stage [34].

Larvicidal activity of essential oils from Blumea mollis [35] and Zingifer officinalis [36] has been reported against $C x$. quinquefasciatus. Larvicidal activity of essential oils from Melaleuca leucadendron, Litsea cubeba and Litsea salicifolia [37], Ocimum suave and O. kilimandscharicum [38] have been reported against Anopheles arabiensis, A. gambiae and $C x$. quinqefasciatus. Larvicidal activities of essential oils from Zanthoxylum armatum [39] and Ocimum canum [40] have been reported against $C x$. Quinquefasciatus, Ae. aegypti and An. Stephensi [41].

Enan suggested that toxicity of constituents of essential oil is related to the octopaminergic nervous system of insects. Relatively few studies have been done on insecticidal activity or fumigant toxicity of caryophyllene oxide. Its high toxicity may result from the inhibition of the mitochondrial electron transport system because changes in the concentration of oxygen or carbon dioxide may affect respiration rate of insect, thus eliciting fumigant toxicity effects [42, 43]. Several reports indicate that essential oils and monoterpenoids cause insect mortality by inhibiting acetylcholinesterase enzyme (AChE) activity. Effects of furanocoumarins and pthalides isolated from Angelica acutiloba Kitagawa var. sugiyame Hikino against Droshophila melanogaster revealed the hypothesis that the insecticidal properties of the plant extracts are connected with the AChE (Acetylcholinesterase) inhibition [44].

Further studies on ethanolic extract from the fruits of Pimpinella anisoides V Brig. exhibited activity against AChE and BChE (Butyrylcholinesterase), with $\mathrm{IC}_{50}$ values. The most abundant constituents of the extract were transanethole that exhibited the high activity against AChE and $\mathrm{BChE}$ with $\mathrm{IC}_{50}$ values [45]. It is confirmed that the insecticidal activity of essential oils and/or mono terpenes is due to several mechanisms that affect multiple targets.

\section{CONCLUSION}

The most attractive aspect of using essential oils and/or their constituents for pest control is their favorable mammalian toxicity because many essential oils and their constituents are commonly used as culinary herbs and spices and as medicines. It is found that the use of biopesticides will help in preventing the discarding of thousands of tons of pesticides on the earth and provide the residue free food and a safe environment to live [46]. The present review study shows a range of essential oils and phytochemicals from varieties of families that exhibit interesting insecticidal properties against several insects and pests [47].

Essential oils are complex mixtures of various molecules. Their biological effects might be either the result of a synergism of all molecules or could reflect only those of the main molecules. Almost literature cases analyses only the main constituents of essential oils. In that sense, for biological purposes, it could be more informative to study the entire oil rather than some of its components because the concept of synergism seems to be important.

Conclusion of our review study suggests that the development of natural or biological insecticides will help to decrease the negative effects of synthetic chemicals. Negative effects refer to residues in products and insect resistance. The utility of plant's essential oils and phytochemicals analysed by many research studies and also others support the Biopesticidal nature of the plant derived essential oils. These oils can be used as a cheap, ecofriendly safe and efficient alternative to the chemical larvicides.

\section{REFERENCES}

[1] Ghosh A, Chowdhury N and Chandra G, (2011). Plant extracts as potential mosquito larvicides. Indian J Med Res, 135(46):581-598.

[2] Kalita B, Bora S and Sharma AK, (2013). Plant essential oils as mosquito repellent - a review. International Journal of Research and Development in Pharmacy and Life Sciences, 3(4):741-747.

[3] Ghoh A, Chowdhury N and Chandra G, (2012). Plant extracts as potential mosquito larvicides. Indian $\mathrm{J}$ Med Res, 135(23):581-598.

[4] Maillard M, Marston A, Hostettmann K, Search for molluscicidal and larvicidal agents from plants in Baladrin M, (1993). Human Medicinal Agents from Plants. American Chemical Society. Washington DC, 534: 256-273.

[5] Wattal BL, Joshi GC and Das M, (1981). Role of agriculture insecticides in precipitating vector resistance. J Communicable Diseases, 13: 71-73.

[6] Qiu H, Jun HW and John WM, (1998). Pharmacokinetics, formulation, and safety of insect repellent $\mathrm{N}, \mathrm{N}$-diethyl-3-methyl benzamide (DEET): a review. J Am Mosq Control Assoc, 14:12-27.

[7] Abagli AZ and Alavo TBC, (2011). Essential oil from bush mint, Hyptis suaveolens, is as effective as DEET for personal protection against mosquito bites. Open Entomol J, 5:45-48.

[8] Sukumar K, Perich MJ and Boobar LR, (1991). Botanical derivatives in mosquito control: a review. $\mathbf{J}$ Am Mosq Control Assoc, 7:210-237.

[9] Ignacimuthu S, (2000). The root of botanicals in combating mosquitoes. Abstracts: Proceedings of 
symposium on recent trends in combating mosquitoes, Loyola College, Chennai, India, 19.

[10] Markouk M, Bekkouche K, Larhsini M, Bousaid M, Lazrek HB, Jana M, (2000). Evaluation of some Moroccan medicinal plant extracts for larvicidal activity. J Ethnopharmacol, 73: 93-297.

[11] Feinstein L, (1952). Insecticides from plants. In: Insects: The year book of agriculture, USA, Washington, 222-229.

[12] Ansari MA, Mittal PK, Razdan RK and Sreehari U, (2005). Larvicidal and mosquito repellent activities of Pine (Pinus longifolia, Family: Pinaceae) oil. J Vector Borne Dis, 42:95-99.

[13] Wiseman Z, Chapagain BP, (2005). Larvicidal effects of aqueous extracts of Balanites aegyptiaca (desert date) against the larvae of Culex pipiens mosquitoes. Afr J Biotechnol, 4 (11): 1351- 1354.

[14] Chowdhury N, Ghosh A, Chandra G, (2008). Mosquito larvicidal activities of Solanum villosum berry extract against the dengue vector Stegomyia aegypti. BMC Complement Altern Med, 8:10.

[15] Ghosh A, Chowdhury N, Chandra G, (2008). Laboratory evaluation of a phytosteroid compound of mature leaves of day jasmine (Solanaceae: Solanales) against larvae of Culex quinquefasciatus (Diptera: Culicidae) and non-target organisms. Parasitol Res, 103: 221-277.

[16] Joseph CC, Ndoile MM, Malima RC, Nkunya MH, (2008). Larvicidal and mosquitocidal extracts, a coumarin, isoflavonoids and pterocarpans from Neorautanenia mitis. Trans R Soc Trop Med Hyg, 98 (8): 451-455.

[17] Cavalcanti ESB, Morais SM, Lima MAA, Santana EWP, (2004). Larvicidal activity of essential oils from Brazilian plants against Aedes aegypti L. Mem Inst Oswaldo Cruz, 99:541-544.

[18] Khanna VG, Kannabiran K, (2007). Larvicidal effect of Hemidesmus indicus, Gymnema sylvestre, and Eclipta prostrata against Culex qinquifaciatus mosquito larvae. Afr J Biotechnol, 3: 307-311.

[19] Yang YC, Le EH, Lee HS, Lee DK, Ahn YJ, (2004). Repellency of aromatic medicinal plant extracts to Aedes aegypti. J Am Mosq Control Assoc, 20 (2): 146-149.

[20] Shivakumar MS, Srinivasan R and Natarajan D, (2013). Larvicidal Potential of some Indian Medicinal Plant Extracts Against Aedes aegypti (L.). Asian J Pharm Clin Res, 6(3):77-80.

[21] Bhupen Kalita, Somi Bora and Anil Kumar Sharma, (2013). Plant essential oils as mosquito repellent - a review. International Journal of Research and Development in Pharmacy and Life Sciences, 3(1)741-747.

[22] Nerio LS, Olivero-Verbel J and Stashenko E, (2010). Repellent activity of essential oils: A review. Bioresource Technology; 101(1):372-378.
[23] Tripathi AK, Upadhyay S, Bhuiyan $M$ and Bhattacharya PR, (2009). A review on prospects of essential oils as biopesticide in insect-pest management. Journal of Pharmacognosy and Phytotherapy; 1(5):52-63.

[24] Ahmed KS, Yosui Y and Lachikawa T,(2001). Effect of neem oil on mating and oviposition behavior of azuki bean weevil, Callosobrucus chinensis L. (Coleoptera: Bruchidae). - Pakistan Journal of Biological Sciences, 4(11):1371-1373.

[25] Manimaran A, Mary Jee Jee Cruz M, Muthu C, Vincent S and Ignacimuthu S, (2012).Larvicidal and knockdown effects of some essential oils against Culex quinquefasciatus Say, Aedes aegypti (L.) and Anopheles stephensi (Liston).Advances in Bioscience and Biotechnology,3:855-862.

[26] Sukumar K, Perich MJ, Boobar LR, (1991). Botanical derivatives in mosquito control: A review. J Amer Mosquito Control Association, 7: 210-237.

[27] Al-Sarar AS, (2014).Chemical Composition, Adulticidal and Repellent Activity of Essential Oils from Mentha longifolia L. and Lavandula dentata L. against Culex pipiens L. J Plant Prot and Path, Mansoura Univ, 5(7):817-826.

[28] Nataya Sutthanont, Wej Choochote, Benjawan Tuetun, Anuluck Junkum, Atchariya Jitpakdi, Udom Chaithong, Doungrat Riyong, and Benjawan Pitasawat, (2010). Chemical composition and larvicidal activity of edible plant-derived essential oils against the pyrethroid-susceptible and -resistant strains of Aedes aegypti (Diptera: Culicidae). Journal of Vector Ecology, 35(1):106-115.

[29] Pavela R, Kaffková K and Kumšta M, (2014). Chemical composition and larvicidal activity of essential oils from different Mentha L. and Pulegium species against Culex quinquefasciatus Say (Diptera: Culicidae). Plant Protect Sci, 50:36-42.

[30] Liu XC, Liu Q, Zhou L and Liu ZL, (2014). Evaluation of larvicidal activity of the essential oil of Allium macrostemon Bunge and its selected major constituent compounds against Aedes albopictus (Diptera: Culicidae). Parasites and Vectors, 7:184.

[31] Rajkumar S and Jebanesan A, (2010). Prevention of Dengue fever through plant based mosquito repellent Clausena dentata(Willd.) M. Roem (Family: Rutaceae) essential oil against Aedes aegyptiL. (Diptera: Culicidae) mosquito. European Review for Medical and Pharmacological Sciences, 14:231-234.

[32] Manzoor F, Samreen KB and Parveen Z, (2013). Larvicidal activity of essential oils against Aedes aegypti and Culex quinquefasciatus larvae (Diptera: Culicidae). The Journal of Animal and Plant Sciences, 23(2):420-424.

[33] Bipul Rabha, Reji Gopalakrishnan, Indra Baruah and Lokendra Singh, (2010). Larvicidal activity of some essential oil hydrolates against dengue and filariasis 
vectors. E3 Journal of Medical Research, 1(1):014016.

[34] Sarita Kumar, Monika Mishra, NaimWahab and RadhikaWarikoo, (2014).Larvicidal, repellent, and irritant potential of the seed-derived essential oil of Apium graveolens against dengue vector, Aedes aegypti L. (Diptera: Culicidae). www.frontiersin.org , 2(147): 1 .

[35] Senthilkumar A, Kannathasan K and Venkatesalu V, (2008). Chemical constituents and larvicidal property of the essential oil of Blumea mollis (D. Don) Merr. against Culex quinquefasciatus. Parasitology Research, 103:959-962.

[36] Pushpanathan T, Jebanesan A and Govindarajan M, (2008). The essential oil of Zingiber officinalis Linn (Zin-giberaceae) as a mosquito larvicidal and repellent agent against the filarial vector Culex quinquefasciatus say (Diptera: Culicidae). Parasitology Research, 102, 1289-1291.

[37] Noosidum A, Prabaripai A, Chareonviriyaphap T and Chandrapatya A, (2008). Excito-repellency properties of essential oils from Melaleuca leucadendron L., Litsea cubeba (Lour.) persoon, and Litsea salicifolia (Nees) on Aedes aegypti (L.) mosquitoes. Journal of Vector Ecology, 33:305.

[38] Kweka EJ, Mosha F, Lowassa A, Mahande AM, Kitau J, Matowo J, Mahande MJ, Massenga CP, Tenu F, Feston E, Lyatuu EE, Mboya MA, Mndeme R, Chuwa $\mathrm{G}$ and Temu EA, (2008). Ethnobotanical study of some mosquito repellent plants in North Eastern Tanzania. Malaria Journal, 7:152.

[39] Tiwary M, Naik SN, Tewary DK, Mittal PK and Yadav S, (2007). Chemical composition and larvicidal activities of the essential oil of Zanthoxylum armatum DC (Rutaceae) against three mosquito vectors. Journal of Vector Borne Diseases, 44:198-204.
[40] Singh NP, Kumari V and Chauhan D, (2003). Mosquito larvicidal properties of the leaf extract of a herbaceous plant, Ocimum canum (Family: Labitae). Journal of Communicable Diseases, 35:43-45.

[41] Cheng SS, Liu JY, Tsai KH, Chen WJ and Chang ST, (2004). Chemical composition and mosquito larvicidal activity of essential oils form leaves of different Cinnamonum osmophloem provenances. Journal of Agricultural and Food Chemistry, 52:4395-4400.

[42] Enan E, (2001). Insecticidal activity of essential oils: octopaminergic sites of action. - Comparative Biochemistry and Physiology Part C, 130: 325-337.

[43] Emekci M, Navarro S, Donahaye E, Rindner M, Azrieli A, (2004). Respiration of Rhyzopertha dominica (F.) at reduced oxygen concentrations. Journal of Stored Products Research, 40: 27-38.

[44] Miyazawa M, Tsukamoto T, Anzai J, Ishikawa Y, (2004). Insecticidal Effect of Phthalides and Furanocoumarins from Angelica acutiloba against Drosophila melanogaster. - Journal of Agricultural and Food Chemistry, 52: 4401-4405.

[45] Menichini F, Tundis R, Loizzo MR, Bonesi M, Marrelli M, Statti GA, Menichini F and Conforti F,(2009). Acetylcholinesterase and butyrylcholinesterase inhibition of ethanolic extract and monoterpenes from Pimpinella anisoides V Brig. (Apiaceae). - Fitoterapia, 80(5):297-300.

[46] Devi N and Maji TK, (2011). Neem Seed Oil: Encapsulation and Controlled Release - Search for a Greener Alternative for Pest Control. - In: M. Stoytcheva (Ed.): Pesticides in the Modern World Pesticides Use and Management. InTech, pp.191-322.

[47] Asgar Ebadollahi, (2013).Plant Essential Oils from Apiaceae Family as Alternatives to Conventional Insecticides.Ecologia Balkanica, 5(1):149-172. 